\title{
A cega
}

The Blind

\section{Yaacov Steinberg*}

Antes de seu casamento, disseram para Hannah, a cega, que aquele destinado a ser seu esposo era um homem viúvo e o comércio de tabaco era sua ocupação. Também prometeram a ela que esse viúvo não possuía filhos de sua primeira esposa. No entanto, e no meio dessa promessa, lembrou-se a mãe de Hannah, que a cega costumava irar-se por mentiras que lhe eram ditas - e, por isso, a velha começou a falar demoradamente a respeito da confortável casa e das duas crianças "que nem lugar ocupavam na casa" e que "silenciosas e tranquilas eram como dois pombos" "Dessa forma, eu ficarei consolada" - jurou a mãe, apressando-se para mudar de tema e voltando-se para o assunto da casa:

- Essa é verdadeiramente uma grande casa, contigua a um grande terreno e há um jardim ali, um grande jardim, pois a casa se encontra nos limites da cidade. Mesmo assim, minha filha, nos primeiros dias após a sua chegada ali, você não deverá se afastar saindo sozinha da casa, pois esse lugar encontra-se na extremidade da cidade. O homem é um comerciante de tabaco e ele está sempre entre os gentios - por isso, é preferível que você permaneça dentro de casa...

A cega ouviu em silêncio às inúmeras recomendações da sua mãe, seus olhos estavam abertos e seus cílios não tremiam, apesar de que o seu coração estava

\footnotetext{
"Yaacov Steinberg é um dos grandes nomes da literatura hebraica da primeira metade do século XX, nasceu em Bila Tserkv, região central da atual Ucrânia, que fazia parte do Império Russo em 1887. Seu pai era açougueiro e ele iniciou seus estudos numa escola rabínica. Em 1901, aos 14 anos, abandonou a cidade natal chegando a Odessa, na época um dos principais centros da intelectualidade judaica. Ali ele conheceu a Haim Nachman Bialik e entrou em contato com a poesia e com a literatura hebraicas. Em 1903, passou de Odessa para Varsóvia onde conheceu o escritor I. L. Peretz. Em Varsóvia, ele começou a participar da imprensa escrevendo tanto em ídiche como em hebraico. Em 1910, mudou-se para a Suíça onde estudou na Universidade de Berna. Retornou a Varsóvia para escrever no Der Fraynd, que foi o primeiro jornal em ídiche a circular diariamente no Império Russo entre 1903 e 1912. Em 1914, Steinberg chegou em Israel e, desde então, passou a escrever apenas em hebraico. Faleceu na cidade de Tel Aviv em 22 de junho de 1947. O conto, escrito em hebraico, foi publicado em Varsóvia em 1912. O texto original está disponível em: <https://bybe.benyehuda.org/read/10313>. 


\section{Arquivo Maaravi}

agitado. Após um silêncio, ela apalpou uma e duas vezes a mesa e perguntou em meio a uma raiva contida:

- Que idade ele tem?

- Dessa forma, eu ficarei consolada, minha filha, pois o homem tem apenas trinta anos - apressou-se a mãe em responder - o casamenteiro jurou isso para mim... um ano a mais ou a menos - não há nisso qualquer importância, minha filha. Oxalá que dessa forma eu consiga ter consolo...

A mãe parou de falar. A cega ficou imóvel, somente sua mão apalpava o canto da mesa uma e outra vez. Era perceptível que o seu coração estava agitado e que ela não acreditava nas palavras da mãe. A velha não voltou a falar mais nada, somente a mão da cega ainda tremia. Ela as removeu com cuidado do canto da mesa e seus lábios sussurraram alguma coisa - um sussurro silencioso de uma pobre mãe.

Na primeira noite, logo após a cerimônia de casamento, a cega esperou até que seu esposo dormisse e, então, começou a apalpar em silêncio os pelos de sua barba. Após fazer isso uma e outra vez, entendeu com toda clareza, que ela fora enganada com uma mentira antes de seu casamento: ele não tinha trinta anos, mas, era um homem avançado em anos que lhe fora dado como esposo. Seu coração ascendeu-se em uma terrível ira, ela permaneceu deitada acordada por um longo tempo e, após cada tossida que seu esposo dava, os seus pensamentos da cega tornavam-se cada vez mais evidentes. "Qual é sua profissão? Deve ser um aguadeiro, um comerciante de trapos ou certamente um artesão de madeiras, um marceneiro?"

Estava claro para ela que um comerciante de tabaco não podia tossir dessa forma... ela revirou-se na cama irada de um lado para outro e sua camisola nova, que ainda nem tinha sido lavada, fez um leve barulho. De repente, a cega desceu da cama e, por alguns instantes, rastejou sobre o chão do quarto, até que suas mãos se chocaram com o par de botas toscas e enrugadas de seu marido, lançando-as irritada para um lado. Levando em consideração as botas de seu esposo, ela pôde imaginar a aparência dele: um judeu magro e de alta estatura que caminhava curvado; sobre a cabeça, um velho solidéu e seus pés pesados caminham por baixo de um longo capote remendado... Assim, ela passou uma longa noite sem dormir e, de manhã, não pôde deixar de escutar o barulho dos passos dele. Quando ele saiu de casa, ela foi atrás com os passos silenciosos de uma pessoa cega que escapuliu e o seguiu por um longo trecho. Eis que ele batia com seu cajado sobre a dura terra do campo, uma batida atrás da outra... Dessa forma, soube a cega que somente um homem velho era capaz de bater na terra lentamente com seu grosso cajado. Quem era, então, esse homem, o seu marido, e qual seria sua ocupação? Agora já estava muito claro que uma mentira fora contada a ela antes de seu casamento; também o comércio de tabaco não era a profissão dele. 


\section{Arquivo Maaravi}

Somente após a festa de Sucot, quando se iniciaram as chuvas e a família convenceu a cega que daria à luz dali a pouco tempo, que suas andanças se tornariam cada vez mais difíceis. Somente então Hannah viajou até o lugar onde seu marido se encontrava. A carroça entrou na aldeia à noite, passou pelas vielas dos judeus que estavam submersas num profundo silêncio e seguiu lentamente até passar por um pântano e por uma feira. Ali, também, pairava um silêncio absoluto, nenhum cão latia, somente o guarda noturno dava algumas batidas com dois paus de madeira e a cega, imediatamente, pode adivinhar que se encontrava no quarteirão da feira com suas lojas. Então, a carroça começou a correr pela trilha sem desviar-se nem para a direita nem para a esquerda. De todos os cantos começaram a ouvir-se latidos de cães e a cega entendeu que eles estavam viajando pelas longas ruas dos gentios. Então, lembrou-se Hannah das palavras que sua mãe havia lhe dito, que a casa de seu esposo encontrava-se nos confins daquela aldeia. Mas qual seria a razão pela qual essa viagem estava se estendendo tanto tempo? Repentinamente, levantou-se um vento e a carroça começou a subir pesadamente pela montanha, - esse era um sinal evidente de que a carroça havia saído dos limites daquele lugar...

Os cavalos finalmente pararam de andar, o cocheiro desceu da carroça e lhe disse que permanecesse sentada e aguardasse até que ele fosse bater na janela, a fim de acordar os membros da casa. Hannah permaneceu sentada na carroça, prestando atenção, como o som dos passos do cocheiro se distanciavam dela. Após isso, ela abaixou os olhos de cansaço. De repente, ela se sacodiu - e os cavalos permaneciam parados, mas um vento tempestuoso se abateu sobre ela de todos os cantos. Onde é que a carroça estaria parada, ela pensou? Estaria ela no campo? Eis que ela escutou, ao longe, a batida que o cocheiro deu na janela da casa. Por um instante, a cega virou sua cabeça para o vazio noturno e, então, tudo tornou-se claro: é assim que se bate sobre uma pequena janela na casa dos gentios. Diferente é o som da batida na janela da casa dos judeus... Seu marido, pois, vive como um gentio, mas a ela foi dito que ele era um comerciante de tabaco! Eis que a cega começou a ouvir os gritos do cocheiro: "Rebe Israel, Rebe Israel" - mas qual seria a razão pela qual seu esposo era chamado de "Rebe Israel, Rebe Israel"?

Finalmente, apareceu o próprio Rebe Israel e ele ajudou sua esposa a descer da carroça, segurando-a a mão dela a conduziu até sua casa. Enquanto atravessavam o corredor, ela reconheceu, no meio daquela caminhada, que aquele era uma espécie de corredor amplo, comum nas casas dos gentios, e, quando a porta foi aberta e um acentuado calor envolveu de uma vez seu rosto, - pensou a cega mais uma vez, que tudo ali não deveria ser como nas casas dos judeus: o fogão para cozinhar se encontrava aparentemente numa das habitações. Após um instante, ela virou sua cabeça em direção ao choro de uma criança. "Este é o pequeno", - respondeu seu marido, apesar de que ela não tinha emitido palavra alguma e nem feito qualquer 
pergunta. O homem saiu para preparar a água para o chá e a cega começou a andar no quarto de um lado para outro.

Enquanto caminhava, ia apalpando com a mão. Ela encontrou a sua frente duas camas: uma delas fria, não estava arrumada, mas na segunda ela percebeu, após apalpá-la, um menino que começou a elevar sua voz num choro profundo. O pai apareceu no quarto, acalmou o menino e conduziu a esposa para mesa e a fez sentar. Quando tudo na casa recobrou o silêncio, ela começou a escutar o barulho das árvores se agitando com o vento outonal. "Será que há um grande jardim na frente de nossa casa?" - e como costumava fazer, no momento em que lhe resultava difícil perceber alguma coisa, a cega abaixou as sobrancelhas e enrugou sua testa para refletir.

Enquanto isso, seu esposo trouxe água quente para o chá e estava a ponto de cortar os cubos de açúcar com uma faca em pequenos pedaços. Repentinamente, caiu um pequeno pedaço de açúcar ao chão - o homem se abaixou para levantá-lo enquanto dava um suspiro típico de um velho. No mesmo instante, a cega apalpou a mesa com sua mão e encontrou a faca e a examinou com seus dedos, para perceber como ela fora feita: se o cabo era grosso e de osso como era típico nas casas dos judeus. Passouse um tempo e o esposo serviu para Hannah um copo de chá e perguntou a sua esposa:

- Devo colocá-la em sua mão?

Hannah enrubesceu e disse:

- Eu posso beber sem ajuda.

A cega deu um primeiro gole e seu coração batia e a taça de chá tremia em sua mão. Ela sabia que seu marido tinha fixado nela seus olhos e a vigiava enquanto ela bebia o chá. De repente, o chá foi derramado do copo que balançava em sua mão, os joelhos dela doíam por causa do chá quente e ela apressou-se para beber do copo que estava agora nas mãos de seu marido.

Repentinamente, quando o esposo começou a arrumar a cama para Hannah, se ouviu uma forte batida na janela e uma voz chamando do lado de fora: "Rebe Israel, Rebe Israel"! Hannah que já tinha começado a tirar seu vestido, permaneceu parada pálida e silenciosa e não conseguia entender, por que seu esposo caminhava lenta e calmamente para abrir a porta - certamente tinha acontecido alguma coisa, essa era razão pela qual batiam à porta no meio da noite. Hannah prestou atenção à estranha conversa entre seu marido e aquele homem desconhecido. Finalmente, ela escutou uma voz grossa e não clara que saia da boca de seu marido quando a porta se fechou.

- O que será que aconteceu? - perguntou-se e seu corpo que estava coberto apenas com a camisola, tremia por inteiro. Seu esposo lhe disse que sua tia tinha adoecido naquela noite e que por isso foram chamá-lo. A cega silenciou e somente seus 


\section{Arquivo Maaravi}

grandes olhos permaneciam amplamente abertos e seu rosto expressava perplexidade - era essa a sensação que preenchia seu coração com uma certa frequência. Hannah foi para a cama, cobriu-se com os quentes cobertores, mas nada conseguia aquecê-la, ela tremia e tremia.

O menino mais velho bateu com suas pequenas mãos sobre o vidro da janela. A cega que estava ocupada naquele momento, apressou-se em sua direção colocando sua mão sobre seu ombro. No entanto, ela não reconheceu, dessa vez, mesmo apalpando com suas mãos, qual era o motivo da alegria que tomou conta do rapaz e qual teria sido a razão da batida que ele deu sobre a pequena janela. Por alguns instantes, ela esteve parada ao lado do rapazinho sem, no entanto, tentar conversar com ele, pois ele tinha a fala pesada, apesar de ter completado já quatro anos de idade. Enquanto permanecia ali parada, pensou, por um instante, que talvez uma doença estaria afligindo o menino e que, por causa da dor, ele estaria balançando e batendo sobre a janela - mas enquanto esse pensamento transcorria em sua mente, a cega passou a mão sobre a cabeça e a bochecha do menino e constatou de imediato que o menino estava saudável e não tinha qualquer doença.

Mas qual seria então a razão pela qual o menino não tinha aprendido até então a falar? Ela raciocinou, concluindo que, seu esposo também era de poucas palavras e que tinha por hábito soltar grunhidos e emitir poucas falas. Certamente, ele se relacionava apenas com os gentios. Seria por isso que o menino também tinha a fala pesada, pois ninguém trocava com ele algumas palavras já que a casa encontrava-se isolada e fora dos limites daquela aldeia. Enquanto remoía seus pensamentos, não esqueceu da sua perplexidade diante das batidas dadas pelos menino. Qual seria a razão pela qual ele posicionou-se ao lado da janela? Teria ele visto alguma coisa do lado de fora?

Ela aproximou-se da janela e encostou sua orelha sobre o vidro. Silêncio. O silêncio era tão grande que ela conseguia ouvir os gritos de um corvo que remexia suas asas ao sobrevoar sobre a janela. Um instante sucedia a outro e Hannah não se mexeu, prestando atenção ao silêncio. Ela teve a impressão de que do lado de fora alguma coisa havia mudado, pois tudo por ali tornou-se mais silencioso e um vento calmo pairava lá fora. O silêncio era semelhante àquele da casa de sua mãe nas noites do Shabat, na hora em que a areia era espalhada sobre o chão. Enquanto a cega permanecia de pé, desenhava-se em sua mente a mudança que acontecia do lado de fora: a primeira neve caia em silêncio. A batida do menino sobre a janela era um sinal de que naquele momento caia neve. Hannah quis perguntar para seu marido, porém o homem não se encontrava em casa. Geralmente, ele costumava ficar em casa, mas acontecia que às vezes alguém repentinamente batia sobre a janela e uma voz do lado de fora chamava: "Rebe Israel, Rebe Israel"! Então seu marido saia de casa por 
algumas horas e, ao retornar, ele sempre lavava suas mãos na água... Para onde ele ia? Ela, por sua vez, não lhe perguntava nada sobre o assunto, pois pouco conversava com seu marido. Tudo que era necessário para o sustento e funcionamento da casa ele mesmo trazia da cidade. Com outras pessoas ela não se encontrava - a respeito do que poderia ela conversar com seu esposo?

A cega saiu dirigindo-se até o fogão para se certificar do gosto dos alimentos que estavam sendo cozidos. De repente, ela escutou um forte barulho do lado de fora. Ela permaneceu no lugar, escutando passos. Seria seu marido se aproximando? No entanto, eram muitos os passos que se ouviam e, para a cega, esse foi o sinal de que muitas pessoas passavam perto de sua casa. Mas de onde teria vindo essa multidão caminhando junto? Seriam gentios retornando da cidade para a aldeia? Hannah sabia reconhecer os passos dos gentios: eram passos compassados e pesados. Mas ela podia facilmente jurar, nesse momento, estar ouvindo passos de judeus. A cega voltou a prestar atenção e lembrou-se de que essa não era a primeira vez que escutava o barulho dos passos de uma multidão vindos do lado de fora. O que aquilo poderia significar? Hannah ergueu o menino, aproximou-o da janela e disse-lhe:

- Yossile, olhe para fora e observa, quem é que está caminhando lá fora?

O menino alegrou-se ao observar lá fora e começou a bater na janela. A cega começou a ouvir as gargalhadas do menino e concluiu que ela deveria concentrar-se nos movimentos do garoto e na sua risada, e então ela seria capaz de entender o que estava acontecendo do lado de fora. Bom seria se ela mesma pudesse sair - fazia muitos dias que ela sentia saudades do som dos passos de um judeu - mas, para ela, tornou-se difícil caminhar: estava grávida e, por essa razão, ela parou de sair de casa.

Hannah continuou em pé diante da janela sentindo falta de uma voz humana. Ela sentia um profundo desejo de ouvir de perto o som de passos... e eis que a porta foi aberta e seu esposo entrou em casa. Antes de dizer qualquer coisa à sua esposa, ele tirou do bolso um punhado de moedas de cobre, espalhou-as sobre a mesa e começou a contar uma a uma ao mesmo tempo em que ele emitia seu habitual grunhido. De acordo com o som vindo das moedas, concluiu a cega que seu marido estava contando dinheiro, então ela perguntou-lhe:

- Israel, você sabe quem eram as pessoas que passaram correndo na frente de casa?

O marido respondeu-lhe com um gemido:

- E o que isso importa a você?

A cega voltou a inquirir:

- O barulho era muito grande... é possível que tenha ocorrido um incêndio?

O esposo responde-lhe e, dessa vez, com um grunhido raivoso:

- Não há necessidade alguma de que você saiba. Senta em casa e pronto! 


\section{Arquivo Maaravi}

Hannah abaixou os olhos como costumava fazer sempre que estava contrariada e não quis responder. Mas ela ouviu que seu marido começou a andar em direção à porta e lhe perguntou:

\section{- Quando é que você comerá o almoço?}

Vindo da mesma direção, a cega ouviu o grunhido do marido dizendo: "Eu tenho coisas mais importantes para fazer do que o almoço" - e, imediatamente, o homem saiu fechando atrás de si a porta. A cega começou a andar até o canto em que seu marido costumava colocar sua bengala e, após alguns instantes de busca, suas mãos encontraram, pois ela se encontrava no lugar habitual. Esse achado sinalizou para a cega que seu marido não teria ido para algum lugar distante, ele teria saído para a casa de algum judeu que morava nas proximidades. Hannah começou a apalpar a bengala em toda sua extensão, cabisbaixa e com a frente enrugada: por que teria seu marido uma bengala comprida e larga como esta?

No início do inverno e com a chegada dos dias frios, a cega deu à luz a uma menina. Noite após noite, a parteira erguia a bebê da cama de Hannah e a deitava em outro lugar. Passaram-se alguns dias até que a cega entendeu que a velha temia que a mãe acabasse sufocando no sono a sua cria. Mas Hannah começou a rir quando entendeu esse temor. Será que apesar de que seus olhos não enxergavam, ela não sabia de nada do que ocorria na casa? No terceiro dia após dar à luz, aconteceu que a parteira lhe serviu sopa numa tigela e Hannah ergueu sua filha por um instante para afastá-la dela, para que não fosse atingida nem pelas mãos nem pelos seus pés, - e, então, pensou a velha que estava observado as ações da cega e seus movimentos, e concluiu que ela não deveria ser totalmente cega e que certamente era capaz de enxergar à luz do dia.

Depois disso, Hannah passou a ter uma outra feição ao levantar do leito onde dera à luz. Sete vezes aumentou a tranquilidade que se estampava em seu rosto. Até então, a cega era de poucas palavras, no entanto, desde o dia em que ela se levantou do leito cessou de falar e somente melodias saiam de sua boca, cantadas sobre o berço da criança. Ao sentar perto do berço da menina, costumavam aparecer também as outras duas crianças, filhos de seu esposo, que apressavam-se e se aproximavam da cega e ficavam a seu lado, um menino de um lado e o outro do outro. Hannah colocava uma mão sobre o ombro de um dos meninos e sua outra mão sobre a cabeça do segundo menino e de sua boca saiam as melodias que ela conhecia. Ela podia passar assim uma hora, até que o esposo voltava para casa, emitindo, ao entrar, o grunhido habitual. Ao escutar esse grunhido, Hannah enrugava a fronte, pois ela não entendia se seu esposo estava irado ou não.

Antes da chegada da festa de Purim, o frio tornou-se mais acentuado. Aconteceu que Hannah saiu uma manhã pelo corredor a fim de trazer galhos para o aquecimento. $\mathrm{O}$ 
vento que vinha de fora e entrava pela porta era muito intenso atingiu a mulher que continuou recolhendo com mãos ouriçadas os galhos das árvores. No instante em que o frio ouriçou ainda mais seu corpo, concluiu a cega que se o frio era tão intenso e nada havia ali que pudesse detê-lo, então sua casa certamente estava erguida no campo. Por um instante, Hannah parou de coletar os galhos, deu alguns passos diante da porta que estava aberta, posicionou-se com os galhos de madeira que ela segurava e começou a escutar o murmúrio do vento naquele campo. A neve que caia lá fora batia em seu rosto, mas Hannah prestava muita atenção ao som que caia a seus pés assim como ao som do vento que carregava a neve para longe. Assim ficou claro para Hannah, que em torno da casa se estendia uma vazia e grande imensidão, e para todo lugar para o qual soprava o vento inclinava a cega sua cabeça para ouvir. Pareceu-lhe, então, que na frente da casa encontrava-se alguma coisa capaz de deter a força do vento. O que seria? Eis que o inverno aproximava-se do fim e com o a chegada dos dias quentes - voltou a cega a refletir - ela rondará a casa por todos os lados para tentar descobrir.

A neve começou a derreter e na casa se escutava todos os dias o barulho das gotículas de água que caiam do telhado. Naquele primeiro dia do início do derretimento da neve, à hora do almoço, abriu o homem, Rebe Israel, sua boca e falou com a esposa com seu habitual grunhido:

- A difteria ronda a cidade.

Após alguns dias, Hannah voltou a ouvi-lo dizendo:

- Todos os dias bebês estão morrendo.

Ao ouvir essas palavras, uma fatia de pão ficou entalada na garganta da cega e uma grande surpresa se espalhou por seu rosto: por que ele estaria falando essas coisas, despertando em seu coração um profundo temor? Daquele dia em diante a cega foi diminuindo os trabalhos caseiros e começou a sentar o tempo todo ao lado do berço da menina e a cada instante passava sua mão sobre o rosto da bebê, certificando-se de que ela encontrava-se bem. Uma vez após outra, curvava-se sobe o berço para escutar a respiração da menina. Estava evidente para Hannah que ela poderia reconhecer com facilidade qualquer doença que atingisse a menina. A cada dia, quando seu marido retornava, ela iniciava uma conversa e perguntava acerca da doença que rondava o povo da cidade. O homem, Rebe Israel, respondia-lhe:

- Os bebês morrem como moscas - ele parecia rosnar.

A cega aos ouvir as palavras ditas pelo marido com impaciência, baixou as sobrancelhas e um tremor passou pelo seu corpo. Por que ele estaria falando dessa forma acerca da morte das crianças, teria ele alguma utilidade ou proveito com isso?

Vieram os dias quentes e poças de água começaram a se formar lá fora. O homem, quando retornava da cidade, estava coberto de lodo até os joelhos - a cega reconhecia 
esse fato pelo andar pesado do marido. Todas as manhãs, os pássaros cantavam diante da janela e o menino mais velho começava, então, a dançar na frente da janela, e somente o espírito da cega estava estremecido ao sentar-se ao lado do berço da menina, mas, para seu esposo, ela não disse que seu coração tinha um mau pressentimento. De repente, saíram da boca de Hannah as palavras que estavam escondidas em seu coração há alguns dias: - Olhe, por favor, Israel, a menina dirigiu-se a mulher ao esposo na hora em que ele havia retornado para casa e se encontrava limpando o lodo das botas - parece que a respiração da menina está ofegante.

Enquanto a cega falava, um grande temor se abateu sobre ela: naquele instante, ela pressentiu que a menina estava doente. A mulher ficou petrificada, baixou as sobrancelhas e seus dedos se cruzaram como que num alicate. Porém, seu esposo nada disse. Ele deixou sua bengala no canto habitual e começou a esfregar suas mãos de forma excessiva. Hannah soube, naquele instante, que a doença da menina não despertou qualquer temor nem preocupação no coração de seu esposo.

Por alguns dias, a bebê esteve doente e o homem, Rebe Israel, saia e retornava de forma habitual. Quando ele se encontrava em casa, ocupava-se com todo tipo de coisa e ficava, às vezes, uma longa hora cortando os cubos de açúcar em pequenos pedaços... A cega estava mergulhada em sua dor, deixou de alimentar o fogão com lenha e nem comida colocou em sua boca. Dia após dia, seu coração começou a encher-se de ódio contra seu marido: por que ele estaria mergulhado na sua habitual tranquilidade e seus passos continuavam contidos e pesados como todos os dias? Uma vez aconteceu que a cega não pode mais conter sua ira e ela foi para cima do marido com gritos e uma forte lamentação:

- Assassino! Você possui olhos, me diga o que a menina tem?

Com o habitual grunhido, o homem fugiu de entre as mãos da cega que ficou em silêncio prestando atenção aos passos do esposo: ela queria saber se aquele homem se aproximou do berço da menina, que enquanto isso emitia o som de sua pesada respiração por toda a habitação. Mas isso não aconteceu. $O$ homem pegou sua bengala e saiu.

A noite, quando se ouvia o ronco do homem em toda a casa e fora se escutava o som das batidas das gotículas de água que caiam do telhado - sentou-se a mulher por horas seguidas ao lado do berço escutando a respiração da pequena. A cega já sabia que a menina iria morrer e, no entanto, força para chorar ela já não possuía, somente seus lábios se movimentavam sussurrando em silêncio: "Que venha o coveiro. A menina eu não lhe entregarei, que venha..." Enquanto a cega estava sentada cabisbaixa e seus lábios se movimentavam, pareceu-lhe que muitos anos haviam se passado enquanto ela permanecia ao lado do berço da menina e que até o final de seus dias ela ficaria sentada naquele lugar. Do lado de fora, ouviu-se mais uma 
batida das gotículas de água que caiam e o ronco pesado do homem repentinamente cessou. A cega abaixou ainda mais a cabeça, seu cérebro estava vazio de qualquer pensamento, seu coração ficou petrificado e ela lentamente ficou submersa no sono. De repente, ela acordou e curvou-se sobre o berço. Pairava o silêncio e a respiração da menina já não mais se ouvia. Por mais alguns instantes, a cega continuou escutando, e então ela pulou do lugar e começou a gritar.

Durante toda aquela noite, a cega passou gritando, mas ao lado do berço ela estava sentada sozinha, pois seu esposo entrava e saia, alternadamente, enquanto Hannah mergulhada em seu choro, não prestava atenção a essa alternância. Ao amanhecer, a cega parou de chorar, pois estava já muito cansada. E, no entanto, do berço ela não se afastou, seus cabelos estavam desgrenhados, sua cabeça movimentava-se sem parar e seus lábios se moviam sussurrando uma e outra vez: "Que venha o coveiro, que venha..." Então ela introduziu sua mão dentro do berço, desejava ela tocar novamente o corpo do bebê morto. Mas a menina já não estava mais no berço. Um grito terrível saiu da sua boca: "Israel, onde ela está?" - mas nenhuma resposta foi emitida. Dores de morte atacaram Hannah enquanto ela procurava o caminho em direção à porta e gritava uma e outra vez: - “Israel, onde está a bebê?"

Do lado de fora, na frente da porta da casa, ela se deteve e ficou parada imóvel e sem palavras. Já era madrugada e o vento não soprava. Uma gota d'água caiu do telhado sobre seu rosto e ela tremeu. A cega abaixou a cabeça e virou seus ouvidos em direção ao campo. Pareceu-lhe que de longe, se aproximava o som dos passos de seu marido. Ela saiu do lugar encontrando o caminho seguindo o som daqueles passos. Por um instante, começou a correr, mas imediatamente tropeçou com alguma coisa e caiu no chão. Ela se levantou e voltou a andar um passo após outro, mas suas pernas iam encontrando e tropeçando em pedras. Foi assim que tropeçou numa grande pedra. Sem pensar muito, ela estendeu suas mãos sobre a pedra e seus dedos começaram a apalpá-la... Um assobio terrível irrompeu da garganta da cega: ela reconheceu que suas pernas a haviam levado ao cemitério.

Tradução: Gabriel Steinberg*

Recebido em: 18/02/2018.

Aprovado em: 26/03/2018.

** Doutor em Língua Hebraica e Professor do Departamento de Letras Orientais da Faculdade de Filosofia, Letras e Ciências Humanas da Universidade de São Paulo. 